\title{
SHYREG, a national database of flood frequency estimation
}

\author{
Patrick Arnaud $^{1, a}$, Philippe Cantet $^{1}$ and Jean Odry ${ }^{1}$ \\ ${ }^{1}$ Irstea -"Recover” Research Unit, 3275 Route de Cézanne, CS 40061, 13182 Aix-en-Provence, France
}

\begin{abstract}
SHYREG method is a regionalized method for rainfall and flood frequency analysis (FFA). It is based on processes simulation. It couples an hourly rainfall generator with a rainfall-runoff model, simplified enough to be regionalized. The method has been calibrated using all hydro meteorological data available at the national level. In France, that represents about 2800 raingauges of the French Weather Service network and about 1800 stations of the hydrometric National Bank network. Then, the method has been regionalized to provide a rainfall and flow quantiles database. An evaluation of the method was carried out during different thesis works and more recently during the ANR project Extraflo, with the aim of comparing different FFA approaches. The accuracy of the method in estimating rainfall and flow quantiles has been proved, as well as its stability due to a parameterization based on average values. The link with rainfall seems preferable to extrapolation based solely on the flow. Thus, another interest of the method is to take into account extreme flood behaviour with help of rainfall frequency estimation. In addition, the approach is implicitly multi-durational, and only one regionalization meets all the needs in terms hydrological hazards characterisation. For engineering needs and to avoid repeating the method implementation, this method has been applied throughout a 50 meters resolution mesh to provide a complete flood quantiles database over the French territory providing regional information on hydrological hazards. However, it is subject to restrictions related to the nature of the method: the SHYREG flows are "natural", and do not take into account specific cases like the basins highly influenced by presence of hydraulic works, flood expansion areas, high snowmelt or karsts. Information about these restrictions and uncertainty estimation is provided with this database, which can be consulted via web access.
\end{abstract}

\section{Introduction}

Flood management involves knowledge of hydrological hazard. The study of hydrological hazard corresponds to the flood frequency analysis (FFA). This determination of hazard is needed on the entire territory. To do this, hydrologists have developed many FFA methods often influenced by the availability of observation data and by the specificities of the local hydrometeorology. In Europe, the FloodFreq COST ES0901 Action (http://www.cost-floodfreq.eu/) has identified the most well-know FFA methods. They include methods enabling an initial estimation of rainfall risk used as an input for more or less empirical rainfallrunoff modelling approaches [30], and methods directly estimating hydrological risk from hydrometric data [8]. All these methods are generally presented in Hydrology reference books [10, 22].

Usually, statistical methods are used to directly fit a probability distribution to the empirical frequency distribution of the studied hydrological variable. The choice of the probability distribution used to estimate flood flows is based on the Extreme Value Theory [11]. In flood frequency analysis, the most common probability distributions are the Generalized Extreme Value (GEV) distribution [17], the Generalized Pareto (GP) distribution

\footnotetext{
${ }^{a}$ Corresponding author: patrick.arnaud@irstea.fr
}

and the Three-Parameter Lognormal (TPLN) distribution. To study ungauged or poorly gauged sites, it is necessary to use a Regional flood frequency analysis (RFFA) [29, 18, 28 and 25] such as the index flood method [12]. These approaches aim to include observations from neighbouring sites to increase the size of the observed data sample.

However, due to the strong non-linearity of hydrological phenomena [19], the extrapolation of frequency distributions to extreme values is still problematic. Calibrating a model based on frequent observations does not guarantee an accurate extrapolation to extreme values. This is why some purely statistical methods rely on estimation of rainfall variability to extrapolate flow probability distribution [16]. By construction, simulation approaches use rainfall data. They have been especially developed to fulfil the temporal data requirement associated with design floods [13]. Such approaches study the statistical properties of observed rainfall and the rainfall/runoff relationship in order to generate rainfall and runoff time series. These simulated time series, which are becoming increasingly common, are then used to extract the desired hydrological characteristics (i.e. quantiles), and can also be used to test the failure of hydraulic structures when subjected to extreme events [23]. Simulation approaches are more and 
more used [24]. Methods differ according to the type of rainfall generator or rainfall-runoff model used. A summary of theses models is presented in the article [7]. In France, there are two simulation approaches, one developed by Electricity of France (EdF) [26], and the other, by Irstea $[1,6]$ (SCHADEX and SHYREG respectively).

The SHYREG method was evaluated in comparison with other FFA and RFFA methods, as part of a national French research project (ANR Extraflo project, https://extraflo.cemagref.fr) [20, 5]. A complete nationwide database on flood flow quantiles estimation has been produced thanks to the implementation of the SHYREG method [6, 27]. This article aims to synthetically present the method, its performance, and resulting databases.

\section{The method}

\subsection{Principle}

SHYPRE is an acronym that means Simulation of HYdrograph for flood PREdiction. The SHYPRE method was initially developed to simulate flood scenarios on a given catchment. It combines an hourly rainfall stochastic model with a conceptual rainfall-runoff model $[9,1]$. This even-based approach focuses on analysis and modelling of hourly rainfall events selected from daily criteria (all daily rainfalls of the event are greater than $4 \mathrm{~mm}$ and one of them must exceed at least $20 \mathrm{~mm}$ ). In France, the number of such events was mapped and varies between 3 and 25 events per year. In order to generate 1,000 years of flood events, we generate the number of events per year for each year (using the Poisson distribution law) and the associated independent rainfall events. These are transformed into flood events, which are associated to a simulation of 1,000 year period. Thus, the method generates a set of flood hydrographs from which empirical flood quantiles are estimated, for different durations and different return periods.

The SHYREG method was developed after SHYPRE and is based on the same principle. Its objective is the regional determination of extreme floods. Its implementation requires the regionalization of both the hourly rainfall generator and the rainfall-runoff model.

First, regionalization of the rainfall generator is based on the use of daily rainfall data, which are more broadly available than hourly data. This process is detailed in a methods guidebook [3]. It relies on the mapping of three daily rainfall variables (related to characteristics of intensity, duration, and frequency) to calibrate the hourly rainfall generator. These three variables, estimated for two seasons (June to November and December to May), were determined and mapped using 2,812 rain gauge stations across the whole French territory, taking into account local environmental and topographical characteristics [2]. The regionalized parameters are used to parameterize the hourly rainfall generator and to simulate at site hourly rainfalls time series. These hourly rainfall time series enable the establishment of a rainfall risk database (intensity-duration-frequency curves for the entire French territory).

Secondly, for regionalisation of rainfall-runoff model, we chose to simplify the model and to convert hourly rainfall into flood flow at a pixel resolution of $1 \mathrm{~km}^{2}$. The use of pixel resolution is necessary because of the at site nature of the rainfall generator (this is not a rainfall field generator). The rainfall generator parameters are set to the regionalised values of the pixel, and then hourly rainfall events are generated at the pixel scale and transformed into flood events with a simplified rainfallrunoff model (described below). Simplifying the model involves using a single parameter. The flood scenarios are used to obtain flow quantiles for each square kilometer (further denominated as specific flows). In order to estimate river flow quantiles, specific flow quantiles are aggregated from all the pixels in the appropriate catchment. Then an areal reduction factor is used to simultaneously take into account both the rainfall areal reduction and the flood routing. This factor only depends on the catchment area and the duration examined. This function is unique on the whole territory and is described in the paragraph below.

\subsection{Calibration}

Calibrating the SHYREG method consists in determining which rainfall-runoff model parameters should be used in order to properly simulate flood events statistically equivalent to the observed ones at gauged stations. This approach was described by Arnaud et al [5].

The first step is to generate specific flow quantiles for each $1 \mathrm{~km}^{2}$ pixel of the territory. In this way, independent hourly rainfall events are simulated at each pixel, using regionalized parameters from the rainfall generator. These hourly rainfall events are converted into independent flood events using an elementary rainfallrunoff model, in which some parameters are fixed (because the model is being used on $1 \mathrm{~km}^{2}$ pixel).

The elementary hydrological model is of the Irstea GR type (www://cemagref.fr/webgr/). It consists of a production reservoir, a routing reservoir and a unit hydrograph [4] and is used in event mode to convert the hourly rain scenarios into flood scenarios at the pixel scale. After testing different structures, the one performing the best to model floods of 12 small gauged basins (each about $1 \mathrm{~km}^{2}$ area) is selected. Thus, it is chosen to fix or impose most of the model parameters except the first reservoir's initial recharge level [5]. This initial recharge level which, called $\mathrm{S}_{0} / \mathrm{A}$, is the only calibrating parameter (varying from 0 to 1 ). Simulations are performed for different $\mathrm{S}_{0} / \mathrm{A}$ values; then flood events are simulated for each of those values, at each pixel. The flood quantiles are extracted empirically from these simulated events. A base flow is added to the generated flows. This base flow corresponds to the estimate of mean monthly specific flow, obtained using the LOIEAU regional method for estimating water resources [14]. While this value is often negligible compared to 
simulated flood flows, it needs to be factored in when calibrating the method, because it enables distinguishing between surface runoff and subsurface runoff, thus avoiding a calibration bias.

As explained above, the generated flood events are assigned to a simulation period and analyzed empirically to calculate the flood quantile values. Since the number of events per year is known (it is one of the rainfall model parameters), there is a correspondence between the empirical frequency and the return period (in year). The flood quantiles are extracted directly from the empirical distribution for return periods that are 100 times shorter than the simulation period to ensure the stability of the empirical frequencies. For example, to obtain millennial quantiles, the equivalent of 100,000 years of rainfall events is simulated and transformed into flood events, then the 1000-year quantiles are estimated by the 100th highest value. This task is performed for each of the 550,000 pixels that cover the metropolitan France. This first step provides for different $\mathrm{S}_{0} / \mathrm{A}$ values, the specific flows for different durations $(d$, with $d=0$ for peak flow) and different return periods $(T)$, noted $q(d, T)$.

The second step is to calculate the flood quantiles at gauged catchment outlets for different $\mathrm{S}_{0} / \mathrm{A}$ parameter values. For each $\mathrm{S}_{0} / \mathrm{A}$ value, the specific flows are averaged over each basin $\left(\overline{\mathrm{q}_{\mathrm{d}, \mathrm{T}}}\right)$. These values are then reduced by a function that depends on catchment surface area $[6,15]$. This function allows factoring in areal reduction of rainfall and flood routing simultaneously. It is represented by equations (1) and (2) depending of duration flows (d):

$$
\begin{gathered}
\mathrm{Q}(\mathrm{d} \geq 24 \mathrm{~h}, \mathrm{~T})=\overline{\mathrm{q}_{\mathrm{d}, \mathrm{T}}} \cdot \mathrm{f}_{1}(\mathrm{~S}) \cdot \mathrm{S} \\
\mathrm{Q}(\mathrm{d}<24, \mathrm{~T})=\mathrm{Q}(24, \mathrm{~T})+\left[\overline{\overline{\mathrm{q}_{\mathrm{d}, \mathrm{T}}}}-\overline{\mathrm{q}_{\mathrm{d}=24, \mathrm{~T}}}\right] \cdot \mathrm{f}_{2}(\mathrm{~S}) \cdot \mathrm{S}
\end{gathered}
$$

The area reduction functions are expressed with the term

$$
f_{i}(S)=\frac{1+\beta_{i}}{1+\gamma_{i} \cdot S^{0,5} \cdot \gamma_{i} \cdot\left(1-S^{\alpha_{i}}\right)}
$$

Where $S$ is catchment area in $\mathrm{km}^{2}$ and $Q(d, T)$ is flow quantile (of duration $d$ and return period $T$ ) calculated at the catchment outlet. Parameters $\alpha_{1}, \alpha_{2}, \beta_{1}, \beta_{2}, \gamma_{1}$ and $\gamma_{2}$ are assumed constant over the metropolitan France and were calibrated in a preliminary study with calibration data.

The third step is the actual calibration of the method and consists in finding the value that minimizes the deviations between the six quantiles obtained from observations (peak flows and mean daily runoff for 2-, 5and 10-year return periods) and the same six quantiles provided by the SHYREG method. The quantiles from observations are estimated by fitting a GEV probability distribution for which the value of the shape parameter is imposed between 0 and 0,4 . The choice of probability distribution is relatively insignificant as long as you are dealing with observed frequencies $(\mathrm{T}<10$ years). For each gauged catchment, then, the SHYREG method can be calibrated by optimizing a single parameter, on which the regionalization process will rely to apply the method over the entire drainage network (including ungauged environments).

Note that local parameter calibration concerns only the rainfall yield (production), via the calibration of the $\mathrm{S}_{0} / \mathrm{A}$ parameter. When it is calibrated, this parameter also allows offset the assumptions made about the other parameters (fixed or regional parameter) which have been set. Since this is not a continuous method, we assumed that the rainfall events, which are generated independently, always occur in a system where the initial state is the same, and given by the parameter $\mathrm{S}_{0} / \mathrm{A}$.

\subsection{Regionalization}

The $\mathrm{S}_{0} / \mathrm{A}$ parameter is evaluated on gauged basins and then regionalized on the study area in order to use the method in ungauged sites. The method of regionalization involves several stages [27]:

The first stage is to search predictors correlated with the optimal parameter values. These predictors are environmental variables averaged over watersheds. To explain the parameter variability, the environmental variables found are: the density of the drainage network, hydrogeology classes and a water balance variable. Although the correlation found is small, with a multiple correlation coefficient $\left(\mathrm{r}^{2}\right)$ of 0.3 , it used to build a map of the parameter explained by the correlation: called "explained $\mathrm{S}_{0} / \mathrm{A}$ ".

The differences between the parameter explained by the correlation and its optimized value are calculated for each catchment. These differences are then mapped by assigning to each pixel of the area, the value of the smaller basin on that pixel (in the case of nested basins). An I.D.W. interpolation (Inverse Distance Weighted) is then performed to take into account regional trends of overestimation or underestimation. A so-called map of residuals which may optionally be smoothed is then obtained. The final map, called "regionalized $\mathrm{S}_{0} / \mathrm{A}$ " is the sum of the "explained $\mathrm{S}_{0} / \mathrm{A}$ " and residuals maps.

Some pixels values are imposed according to the land use (based on the Corine land Cover Database). These 1$\mathrm{km}^{2}$ pixels are those mainly affected by the presence of urban or suburban area and lakes that are considered highly impermeable. 


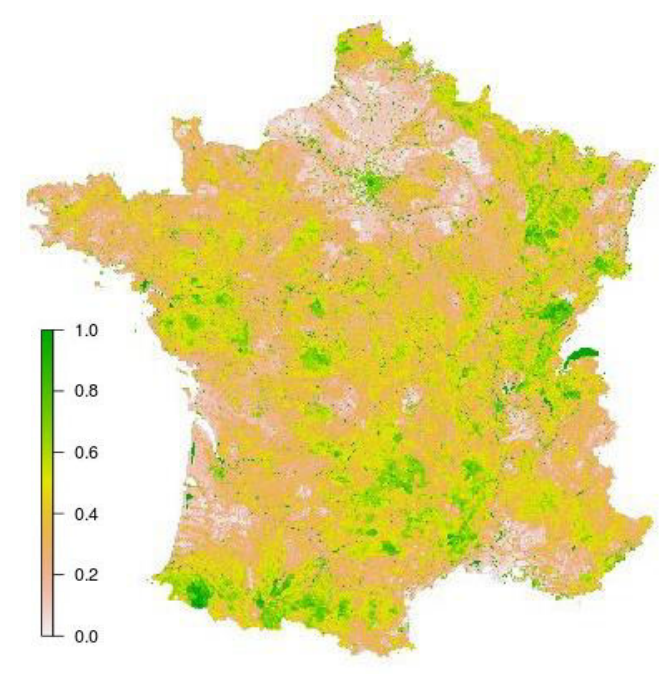

Figure 1. Regionalized $\mathrm{S}_{0} / \mathrm{A}$ map.

\section{Advantages}

\subsection{National coverage}

The method was applied on the dataset of 1800 watersheds from the national database (Hydro). These basins are referred as uninfluenced and considered "reliable" in high water range by managers. These basins have long time series (at least 10 years of data) and their areas do not exceed $2000 \mathrm{~km}^{2}$. During the application of the method on the dataset, a first step consists in checking if the method fits properly with only one parameter. Table 1 shows the Nash-Sutcliffe Model Efficiency (NSME) criterion calculated on 10-year quantiles regarding GEV estimations. To remove the surface effect that explains a large part of the variability of flows, the results are calculated on pseudo-specific flows (division by the quantity $\mathrm{S}^{0,8}$ where $\mathrm{S}$ is the basin area). $\mathrm{QPS}_{10}$ and QJS $_{10}$ are respectively 10-year specific peak flow peaks and 10-year daily flow. We can see that normal flood quantiles are well reproduced by the method on gauged basins by using only one parameter characterizing the production basins.

The next step is the regionalisation of the method. The presence of nested basins does not allow associating each pixel of the basins to its optimized value. Indeed in the case of nested basins, some pixels belong to two (or more) basins and therefore can be associated with different optimal parameter value.

We have chosen to assign each pixel parameter value of the smaller basin to which this pixel belongs. In this case, the regionalization of the parameter $\mathrm{S}_{0} / \mathrm{A}$ does not ensure to find the optimal value of the parameter and therefore to refind the flood quantiles obtained during the calibration. Table 1 shows the performance of the method calculated on current quantile, obtained on gauged basins by fully regionalized method.

The results presented in Table 1 show a good restitution of flood quantiles (peak flows and daily flows 10 -year return periods).

\begin{tabular}{|c|c|c|c|}
\hline \multicolumn{2}{|c|}{ Local } & \multicolumn{2}{c|}{ Regional } \\
\hline QPS $_{10}$ & QJS $_{10}$ & QPS $_{10}$ & QJS $_{10}$ \\
\hline 0,99 & 0,95 & 0,95 & 0,94 \\
\hline
\end{tabular}

Table 1. NSME criteria of local and regional 10year-values estimated with SHYREG method compare to local GEV estimation.

However, to judge the relevance of the SHYREG method results a complete analysis with calibration / control procedures was performed.

\subsection{Performances}

To evaluate the performance of the method, the 1800 studied basins were divided into two groups: one sample used for calibration of the method (calibration and regionalization of the parameter $\mathrm{S}_{0} / \mathrm{A}$ ) and the other one to control the method (basins are not used during calibration and regionalization phases).

Two samplings were carried out:

Half: $50 \%$ of basins are randomly selected for calibration and the remaining 50\% are used for control.

Downscaling: the larger basins are selected for calibration ( 872 basins with $\mathrm{S}>100 \mathrm{~km}^{2}$ ) and the smaller basins (basins with 418 remaining $\mathrm{S}<100 \mathrm{~km}^{2}$ ) are used for control.

A comparison was made with the only other regionalized method, available throughout France: the method Crupedix. This method involves establishing a relationship between flow quantiles, rainfall quantiles and watershed area. Initially established for 10-year peak flows (QP10) is readjusted here on peak flows, but also on 10-year daily flows (QJ10). An optimization of coefficients ( $a, b, c$ and d) of the formula (4) has been performed, in both cases:

$$
\mathrm{Q}=\mathrm{a} \cdot \mathrm{R} \cdot\left(\frac{\mathrm{PJ} 10}{\mathrm{c}}\right)^{\mathrm{b}} \cdot \mathrm{S}^{\mathrm{d}}
$$

In (4), $\mathrm{R}$ is the regional correction coefficient of Crupedix method. It was mapped and its values range between 0.13 and 1.75 . PJ10 is the 10 -year daily rainfall (here provided by the SHYREG method) and $S$ is the watershed area.

Table 2 comparing NSME criteria obtained by comparison of local and regional value estimated with application of both approaches: SHYREG method and "Crupedix" formula.

The SHYREG method leads to significantly better results than a Crupedix formulation. We also note that the formulation Crupedix is inadequate to explain the variability of specific daily flows, even after calibrating the coefficients. When we look "downscaling" sampling, we find that the validation results are very bad for the Crupedix formulation. The downscaling is difficult to apprehend by a simple formulation. 


\begin{tabular}{|c|c|c|c|c|c|}
\hline \multirow{2}{*}{ Method } & \multirow{2}{*}{ Sampling } & \multicolumn{2}{|c|}{ Calibration } & \multicolumn{2}{|c|}{ Control } \\
\hline & & $\mathrm{QPS}_{10}$ & $\mathrm{QJS}_{10}$ & $\mathrm{QPS}_{10}$ & QJS $_{10}$ \\
\hline SHYREG & \multirow{2}{*}{ Half } & 0,88 & 0,88 & 0,77 & 0,81 \\
\hline Formula (4) & & 0,69 & $-0,15$ & 0,58 & $-0,66$ \\
\hline SHYREG & \multirow{2}{*}{ Downscaling } & 0,88 & 0,86 & 0,57 & 0,74 \\
\hline Formula (4) & & 0,71 & 0,35 & $-0,11$ & $-4,2$ \\
\hline
\end{tabular}

Table 2. NSME criteria obtained by comparison of local and regional value estimated with application of both approaches: SHYREG method and "Crupedix" formula

We see here a disadvantage that represents a simple approach like "Crupedix" to estimate rates of different durations and different frequencies. Indeed, a calibration of coefficients and of the regional correction coefficient (R) would probably require for each duration and each return period. The SHYREG method has the advantage to provide correct results for all durations flows from the regionalization of a single parameter. Similar results are found by multiplying the sampling of calibration / control [27].

SHYREG method was also compared with other FFA methods in the ANR project Extraflo [21]. The method's reliability indexes have very good values, better than those found with the standard statistical methods that were tested. A supplementary study showed that to obtain reliability criteria as good as SHYREG's, you would need to use a regional statistical distribution $[20,5]$. The method's reliability is linked to the type of approach, which proposes an estimation of extreme flows based on regional extreme rainfall data. It would appear that an approach based on rainfall data leads to particularly relevant flood flow extrapolation. This type of rainfall data provided by the method was also found to be reliable and stable. It was also demonstrated that the method enables relevant "predictive" estimates, e.g., by assigning correct return periods to the record values missing from the calibration data.

\section{A national database}

The regionalization of the parameter $\mathrm{S}_{0} / \mathrm{A}$ allows to implement the method on all the pixels of the studied area. A specific flow database is thus obtained associated with the method. This database must necessarily be used with the agglomeration and areal reduction coefficient of the SHYREG method. This procedure is then performed on the entire territory using the flow directions which enable to determine the contour and surface of any watershed numerically.

For the national implementation of the SHYREGflow basis, the flow directions at a pitch of $50 \mathrm{~m}$ provided by the SCHAPI are used. This database of flow directions was corrected to position on the river system of the Carthage database and finds the outlets of hydrometric stations. This base can be considered a national baseline for the demarcation of topographic watersheds. Automatic calculation of catchment boundaries led to the development of a national basin database of almost 140,000 basins associated with hydrographical sections.

From these data, SHYREG quantiles were calculated according to several resolutions. Peak flows of 10, 30, 100,300 and 1000-year return periods were calculated at any point over the river network on a 50 -meter grid, and for any pixels drained by more than $5 \mathrm{~km}^{2}$.

Quantile flows of different durations (from instantaneous to 72 hours) and for 2, 5, 10, 20, 50, 100, 500 and 1000-year return periods, were calculated on about 140000 outlets of the national basin database.

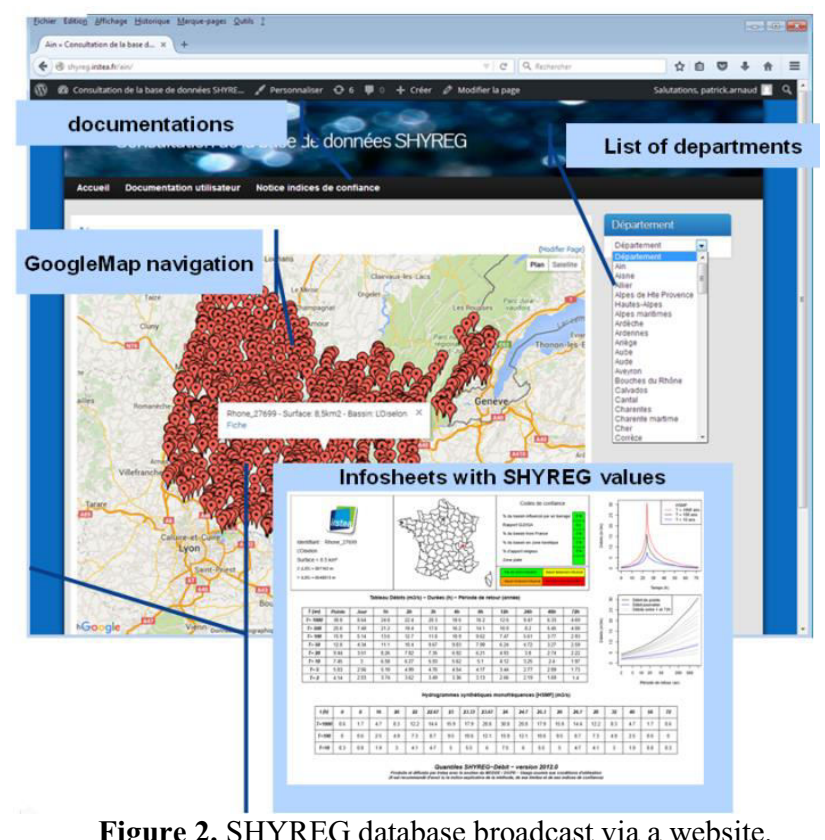

Figure 2. SHYREG database broadcast via a website.

The SHYREG databases are the result of the application of the method SHYREG on the national territory. SHYREG is a regional FFA approach resulting from the use of the most exhaustive hydro meteorological information, available in the national databases. It integrates the spatial variability of rainfall statistics. This approach has the advantage of being homogeneous throughout the country and provides estimating all the characteristics of floods with a single regionalization.

\section{Conclusions}

The SHYREG method is an FFA method based on simulation of processes. It includes a regionalization of both the hourly rainfall generated and the simple hydrological model. The approach aims to be fully regionalized, so it is necessary to make modelling assumptions to limit the number of parameters to reduce equifinality problems. This may be a problem if the simplifications significantly degrade the performance of the method. The results of the method SHYREG on gauged basins show that despite the simplifications, the method is able to fit observations and to produce accurate results.

The limited number of parameters also increase the stability of the approach. This quality is linked to both the parsimonious approach and the parameterization based on 
average values (for the rain model) or calibrated against common values (for the hydrological model).

The regionalization of the approach tries to fully use information provided by climate and environmental descriptors. It is also based on information that aims to be as uniform and comprehensive as possible. In the implementation of the approach, all hydro-climatological data available in national data banks, has been exploited.

Improvements in the regionalization of hydrological model are however expected. For instance, through research on improvement on the areal reduction function, fixing the parameters by homogeneous sub-regions rather than single values over France, researching more appropriate downscaling methods with the notion of upstream-downstream dependency, etc...

However, the method has performances that are widely acceptable for operational use, particularly considering the lack of recent operational approaches in the national territory. SHYREG offers more uniform and consistent estimation of all statistical characteristics of hydro-meteorological hazards (rainfall and flow frequency estimation for different durations) which are for the evaluation of hydrological risks.

One should be aware of the limits of use of the approach. As any method, the estimates provided by the SHYREG method are subjected to some uncertainties. SHYREG method was calibrated on so-called "natural" catchments. However some basins have behaviours that can be impacted by different configurations that are not suitable for the method use such as karsts, highly urbanized basins, basins affected by hydraulic structures...

To report these particular areas on which SHYREG quantile have however been calculated, a confidence index is proposed to describe the degree of method applicability. This index is a combination of several indices that characterize the percentage of the basin associated with a limit of use. These zones of influence are currently associated with the presence of large dams, karsts, and strong snow regime flood expansion areas. The objective of this index is to educate users about cases where local characteristics of the catchment make the SHYREG quantiles unsuitable. Currently SHYREG database broadcast via a website.

\section{References}

1. Arnaud P. and Lavabre J. (2002) Coupled rainfall model and discharge model for flood frequency estimation. Water Resource Research. 38(6).

2. Arnaud P., J. Lavabre, et al. (2008) Regionalization of an hourly rainfall generating model over metropolitan France for flood hazard estimation. Hydrological Sciences Journal. 53(1) 34-47.

3. Arnaud P. and J. Lavabre (2010) Estimation de l'aléa pluvial en France métropolitaine. QUAE, Paris. Update Sciences \& Technologies. $158 \mathrm{p}$.

4. Arnaud P. et al. (2011) Sensitivity of hydrological models to uncertainties in rainfall input. Hydrological Sciences Journal 56(3) 397-410.
5. Arnaud P., Cantet P. and Aubert Y. (2016) Relevance of an at-site flood frequency analysis method for extreme events based on stochastic simulation of hourly rainfall. Hydrological Sciences Journal 61(1) 36-49.

6. Aubert Y., Arnaud P., Ribstein P. and Fine J.A. (2014) La méthode SHYREG débit, application sur 1605 bassins versants en France Métropolitaine Hydrological Sciences Journal 59(5) 993-1005.

7. Boughton W. and Droop O. (2003) Continuous simulation for design flood estimation - a review. Environmental Modelling \& Software 18(4) 309-318.

8. Castellarin A. et al (2012) Review of applied statistical methods for flood frequency analysis in Europe : WG2 of COST Action ES0901.

9. Cernesson F., Lavabre J. and Masson J.M. (1996) Stochastic model for generating hourly hyetographs. Atmospheric Research 42, 149-161

10. Chow V.T., Maidment D.R., May s L.W. (1988) Applied hydrology. McGraw-Hill, Inc. 572 p.

11. Coles S. (2001) An introduction to Statistical Modeling of Extreme Values. Springer Series in Statistics, ed. Springer-Verlag. London: SpringerVerlag. 210 p.

12. Darlymple T. (1960) Flood-frequency analysis. Water Supply Pap., 1543A - US Geol Surv.

13. Eagleson P.S. (1972) Dynamics of flood frequency. Water Resources Research 8(4) 878-898.

14. Folton N. and J. Lavabre (2006) Regionalization of a monthly rainfall-runoff model for the southern half of France based on a sample of 880 gauged catchments. IAHS Publication Large Sample Basin Experiments for Hydrological Model Parameterization. 4, 264-277

15. Fouchier C. (2010) Développement d'une méthodologie pour la connaissance régionale des crues. Thèse de Doctorat de l'Université Montpellier II. $202 \mathrm{p}$.

16. Guillot P. and Duband D. (1967) La méthode du Gradex pour le calcul de la probabilité des crues à partir des pluies. I.A.S.H. Publication, 84.

17. Hosking, J.R.M. and Wallis, J.R. (1993) Some statistics useful in regional frequency analysis. Water Resour. Res., 29(2) 271-281.

18. Hosking J.R.M. and Wallis J.R. (1997) Regional frequency analysis: an approach based on Lmoments. Cambridge University Press.

19. Katz R.W., Parlange M.B. and Naveau P. (2002) Statistics of extremes in hydrology. Advances in Water Resources 25(8-12) 1287-1304.

20. Kochanek, K., B. Renard, P. Arnaud, Y. Aubert, M. Lang, T. Cipriani, and E. Sauquet (2014) A databased comparison of flood frequency analysis methods used in France. Natural Hazards and Earth System Sciences 14, 295-308.

21. Lang M., Arnaud P., Carreau J. Delizeau L., Garavaglia F., Latapie A., Neppel L., Paquet E., Renard B. Soubeyroux J.-M., Terrier B., Veysseire J.-M., Aubert Y., Auffray A., Borchi F., Bernardara P., Carre J.-C., Chambon D., Cipriani T., Delgado J.L., Doumenc H., Fantin R., Jourdain S., Kochanek K., Paquier A., Sauquet E. et Tramblay Y. (2014) 
Résultats du projet Extraflo (ANR 2009-2013) sur l'estimation des pluies et des crues extrêmes. La Houille Blanche. 2 : 5

22. Lang M. et Lavabre J. (2007) Estimation de la crue centennale pour les plans de prévention des risques d'inondations, QUAE, Paris. Update Sciences \& Technologies. $232 \mathrm{p}$.

23. Lavabre J., Arnaud P. Royet P., Fine J-A., Delichere S., Fang Z.-X. et Foussard F. (2010) Crue de projet ou cote de projet ? Exemple des barrages écrêteurs de crue du département du Gard. La Houille Blanche 2(2010) 58-64.

24. Li J. et al. (2014) An efficient causative event-based approach for deriving the annual flood frequency distribution. Journal of Hydrology 510(0) 412-423.

25. Merz R. and Blöschl G. (2005) Flood frequency regionalisation-spatial proximity vs. catchment attributes. Journal of Hydrology, 302(1-4), 283-306.

26. Paquet E. et al. (2013) The SCHADEX method: A semi-continuous rainfall-runoff simulation for extreme flood estimation. Journal of Hydrology, 495(0), 23-37.

27. Organde D., Arnaud P., et al. (2013) Régionalisation d'une méthode de prédétermination de crue sur l'ensemble du territoire français: la méthode SHYREG. Revue des sciences de l'eau 26(1) 65-78

28. Ribatet M. et al. (2007) A regional Bayesian POT model for flood frequency analysis. Stochastic Environmental Research and Risk Assessment 21(4) 327-339.

29. Stedinger J.R. and Tasker G.D. (1985) Regional hydrologic analysis: 1. Ordinary, weighted and genaralized least squares compared. Water Resources Research 21(9) 1421-1432.

30. Willems, P., et al. 2012. Review of European simulation methods for flood-frequency-estimation. WG3: Flood frequency analysis using rainfall-runoff methods. Report of Cost Action ES0901. 66 pages. 